Institute of $\mathbf{F}_{\text {ood and }} \mathbf{A}_{\text {gricultural }} \mathbf{S}_{\text {ciences }}$

\title{
Manual de los Reglamentos de Agua de Florida: Acta de Recuperación y Conservación de Recursos ${ }^{1}$
}

\author{
Michael T. Olexa, Laura Minton, Dulcy Miller, y Sarah Corbett ${ }^{2}$
}

\section{Agradecimientos}

Los autores agradecen a Richard Budell de la Oficina de Política del Agua Agrícola del Departamento de Agricultura y Servicios al Consumidor de Florida. Los autores también agradecen a David H. Hammonds, Consultor del Programa de Salud Ambiental, Oficina de Programas de Aguas de Drenaje en el Sitio, del Departamento de Salud de Florida, y a Edward A. Bettinger, Consultor del Programa de Salud Ambiental, Oficina de Programas de Agua del Departamento de Salud de Florida.

\section{Sinopsis}

El Acta de Recuperación y Conservación de Recursos (ARCR) se ha propuesto como amplia autoridad para todos los aspectos del manejo de desechos peligrosos. Tiene requerimientos separados para las categorías de generadores, transportadores e instalaciones para tratamiento, almacenaje o eliminación de desechos peligrosos. Estos requerimientos, que incluyen otorgar permisos para muchas instalaciones y mantener un registro exhaustivo de todas las fases de manejo, se han propuesto para seguir el movimiento y el manejo de los desechos, hasta llegar a su punto final de eliminación. Esto es conocido como el enfoque "desde la cuna hasta la tumba" para monitorear desechos.

1. Este es el documento EDIS FE066, una publicación del Department of Food and Resource Economics, Florida Cooperative Extension Service, Institute of Food and Agricultural Sciences, University of Florida, Gainesville, FL. Publicada Noviembre 2002. Por favor visite la página electrónica EDIS en http://edis.ifas.ufl.edu.

2. Michael T. Olexa, es profesor del Department of Food and Resource Economics, Florida Cooperative Extension Service, Institute of Food and Agricultural Sciences, University of Florida, Gainesville, FL; y miembro de Florida Bar; Presidente de Agricultural Law Committee of The Florida Bar; y Director del Agricultural Law Center. Laura Minton, Dulcy Miller, y Sarah Corbett son estudiantes graduadas de Levin College of Law, University of Florida, Gainesville, FL. Filiberto Reyes-Villanueva fue el traductor de la versión en ingles al español.

Esta publicación esta diseñada para proporcionar información precisa, actualizada y autorizada sobre esta material. Sin embargo, ya que las leyes, reglas administrativas y decisiones de la corte, sobre las cuales están basados, están sujetas a revisión constante; algunas partes de esta publicación podrían ser obsoletas en cualquier momento. Esta publicación es distribuida bajo el entendimiento que los autores no están involucrados en ninguna representación legal u otros servicios profesionales, y que la información contenida aquí no debe ser considerada como un substituto de una asesoria legal. Esta publicación no esta completa en proporcionar toda la información para lograr el cumplimiento de las leyes y reglamentos que gobiernan la protección del agua. Por estas razones, el uso de estos manuales por cualquier persona constituye un acuerdo para mantener libre de daño a los autores, al Florida Cooperative Extension Service, al Institute of Food and Agricultural Sciences, y a la University of Florida por cualquier demanda por responsabilidad de daños, o gastos en que pueda incurrir cualquier persona, como un resultado de hacer referencia o confianza sobre la información contenida en esta publicación. Esta publicación fue apoyada financieramente por el Florida Department of Agriculture and Consumer Services.

EI Instituto de Alimentos y Ciencias Agrícolas es Un empleador que opera bajo Acción Afirmativa y provee Oportunidades Igualitarias, dedicado a promocionar la investigación, a información educativa y otros servicios, únicamente a los individuos e instituciones que operan baj discriminación sin considerar color, raza, sexo, edad, incapacidad u origen. Para más información sobre como obtener otras publicaciones de la extensión, comuníquese con la oficina de Servicio de Extensión de su condado. Servicio de Extensión de la Florida / Instituto de Alimentos y Ciencias Agrícolas / Universidad de la Florida / Christine Taylor Waddill, Decana. 
El ARCR también establece estándares para la eliminación de desechos sólidos, los cuales incluyen:

- basuras, restos y sedimentos.

- desechos líquidos, semisólidos y gases confinados.

- desechos resultantes de las operaciones industriales, comerciales, de minería y agrícolas.

Sin embargo, el drenaje doméstico, el flujo de retorno de irrigación, o contaminantes cubiertos bajo el permiso de la SNEDC del Acta de Aguas Limpias como fuentes de punto, no son considerados desechos sólidos y por lo tanto no están sujetos a los estándares de eliminación de la ARCR.

\section{¿Quién Aplica la ARCR?}

La Agencia de Protección de Ambiente (APA) es responsable para implementar y aplicar la ARCR, para establecer los criterios para clasificar "desechos peligrosos", y para enlistar aquellos a los cuales el ARCR se aplica automáticamente.

\section{¿Cómo es Aplicada la ARCR?}

Los permisos son requeridos bajo la ARCR para cualquiera quien posea u opere una instalación para el tratamiento, almacenaje o eliminación de desechos peligrosos. Los generadores y transportadores pueden operar sin un permiso de la APA, pero deben obtener un número de identificación y se les pedirán reportes para archivo por la APA a intervalos regulares, dependiendo de la cantidad y tipo de desecho que ellos manejen.

La APA mantiene amplia autoridad para requerir pruebas, inspecciones o monitoreo adicional, cuando esta determine que hay un peligro para la salud o para el medio ambiente de parte de la instalación. Esto es especialmente cierto con respecto a las instalaciones de desechos peligrosos permitidos. No se requieren permisos federales para eliminación de desechos sólidos, aunque si existen regulaciones federales al respecto.

\section{¿Qué son los Castigos?}

La APA puede emitir sus propias reglas administrativas para cobrar los gastos en que incurre para el monitoreo o evaluación. La APA esta también autorizada para iniciar acciones civiles para ejecutar sus ordenes o reglas.

La ARCR autoriza a los ciudadanos privados a emprender demandas civiles para aplicar sus disposiciones contra los infractores, además permite procesos legales civiles contra la APA o el administrador del estado para obligar la aplicación de la ARCR.

El ARCR aplica multas civiles de hasta $\$ 25,000$ por día de desacato. El grado de los castigos penales dependerá de si el violador conocía la violación (\$50,000 por día y cinco años de prisión), o conociéndola puso a otras personas en peligro (\$250,000 por día y 15 años de prisión). La organización es tal que un caso de desacato, puede estar sujeto a una multa de hasta un millón de dólares más el fallo de culpabilidad para los individuos asociados al caso.

\section{Fuente}

Código 42 de los Estados Unidos secciones 6901 a 6987. 